\title{
Experimental Investigation of Four-Point Flexural Behavior of Textile Reinforcement in Geopolymer Mortar
}

\author{
Hiep Le Chi and Petr Louda
}

\begin{abstract}
This paper describes an investigation of four-point flexural behavior of geopolymer composite specimens which made of textile reinforced geopolymer mortar. The two different types of mesh (basalt and carbon mesh) and their various aperture sizes were used as reinforcement. In this experimental work, only two mesh layers (for each type of textile) reinforced in geopolymer mortar are considered. All 21 plate specimens including reference specimens, each of size $360 \times 180 \times 20 \mathrm{~mm}^{3}$, have been tested for four-point bending strength. Besides that, 15 samples with dimension 30x30x150 $\mathrm{mm}^{3}$ and 15 samples of diameter size $45 \mathrm{~mm} \times$ length $90 \mathrm{~mm}$ have been measured for evaluating the mechanical properties of geopolymer mortar matrix. The results have shown that geopolymer composite specimens with carbon meshes have both the flexural strength and deflection higher than those with basalt meshes. Besides, the decrease of aperture size of mesh improves significantly the flexural strength due to increase specified number of yarns.
\end{abstract}

Index Terms-Geopolymer, four-point flexural strength, textile, compressive strength, carbon mesh, basalt mesh.

\section{INTRODUCTION}

Textile-reinforced concrete (TRC) is a composite material composed of a fine-grained matrix with textile materials such as alkali-resistant glass, carbon, basalt or polymer replacing usual steel reinforced bars. The major advantages of TRC are its high tensile strength and pseudo-ductile due to its tolerance of multiple cracking [1]. The further advantages of these materials such as reinforcement have the ability to withstand corrosion, aggressive environments and therefore does not require strong covering layers in contrast to classical steel-reinforced concrete, where required cover layer should be enough thickness to protect the corrosion of steel-reinforcement during the lifetime of the structure. Due to these reasons, it is resulting in thinning and reduction of the mass of the whole structure. Thanks to their excellent material properties, the TRC composites are used in a wide range of applications such as strengthening and repair in structural elements, thin-walled elements, façade elements, bridges and also freeform and lightweight structures [2]-[7]. However, the TRC is not an environmentally friendly composite due to the use of the cement rich binder. The production of Portland cement is responsible for around 5\%

Manuscript received May 5, 2018; revised July 12, 2018. This work was supported in part by in part by project, application of geopolymer composites as fire, AGK."

Hiep Le Chi is with the Department of Material Engineering, TechnicalUniversity of Liberec, Czech Republic (e-mail: lechihieptul09@gmail.com).

Petr Louda is with Technical University of Liberec. He is now ahead ofthe Department of Material Engineering, Technical University of Liberec, Czech Republic (e-mail: Petr.louda@tul.cz). of the global $\mathrm{CO}_{2}$ emissions. The appearance of the new material called geopolymer presents a promising technology direction for the construction industry.

Geopolymers are considered as an environmentally favorable choice due to the production of its raw materials may reduce $\mathrm{CO}_{2}$ emission by up to six times [8]. Moreover, geopolymers are believed to display good mechanical strength in elevated temperature due to their ceramic structure. Therefore, concretes produced using geopolymers may obtain greater fire resistance as compared to conventional concretes produced using Portland cement Daniel L. Y. Kong [9] showed that metakaolin-based geopolymers dis played more severe degradation compared to fly-ash based geopolymer at a high temperature above $700^{\circ} \mathrm{C}$. Nevertheless, at a lower temperature than $500^{\circ} \mathrm{C}$, these materials exhibit the similar mechanical properties and provide enough stability without showing signs of spalling [10]. Geopolymers are ceramic-like inorganic polymers produced at lower temperature, generally below $100^{\circ} \mathrm{C}$ [11] These materials are produced by activating the solid aluminosilicate source with an alkaline solution, which is usually alkaline hydroxides and/or silicate solution based on sodium or/and potassium [12]. The process of the formation geopolymer composes the dissolution of the solid alu minosilicate framework, followed by the condensation of free silicates and aluminates, which forming a 3D configuration. This structure consists of cross-linked $\mathrm{SiO}_{4}$ and $\mathrm{AlO}_{4}$ tetrahedra, where the negative charge is balanced by the positive charges of the alkali ions $\left(\mathrm{Na}^{+}, \mathrm{K}^{+}\right)$[11].

This paper presents information on the impact of four-points flexural test of geopolymer composite panels after the addition of basalt and carbon fibers in the form of networks into the geopolymer mortar.

\section{EXPERIMENT AL PROCEDURE}

\section{A. Geopolymer Mortar Matrix}

Baucis LNa alu mino-silicate geopolymer binder based on metakaolin was purchased from Ceske Lupkove Zavody, a.s. Czech Republic (in weight percent: $\mathrm{SiO}_{2}-47.4 ; \mathrm{Al}_{2} \mathrm{O}_{3}-$ 29.7; $\mathrm{CaO}$ - 14.5; $\mathrm{MgO}-2.6 ; \mathrm{TiO}_{2}-1.8 ; \mathrm{Fe}_{2} \mathrm{O}_{3}-0.5 ; \mathrm{K}_{2} \mathrm{O}-$ $\left.0.3 ; \mathrm{Na}_{2} \mathrm{O}-1\right)$ along sodium silicate activator of modul 1.73 (in weight percent: $\mathrm{SiO}_{2}-20.72 ; \mathrm{Na}_{2} \mathrm{O}-12.33 ; \mathrm{H}_{2} \mathrm{O}-66.68$ ). The metakaolin geopoly mer was synthesized from calcined kaolin and shale clay residues with $\mathrm{Si} / \mathrm{Al}$ ratio of 2.0. the kaolin was main ly composed of kaolinite with small a mounts of quartz, whereas shale clay was composed of kaolin ite with low a mount of quartz and anatase. At first, kaolin and shale clay were passed in a rotary kiln to obtain in $30-70 \%$ loss of kaolinitic structure due to dehydroxylation. Further, it was converted to metakaolin by additional calculations at $750^{\circ} \mathrm{C}$ 
for $10 \mathrm{~h}$ in bath oven.

Two different types of silica sand were used as the fine aggregates for geopolymer mortar matrix (grain size: $0-$ $0.063 \mathrm{~mm}$ and $0.6-1.25 \mathrm{~mm}$ ).

The geopolymer mixture was prepared as a two-component system using aluminosilicate source and sodium silicate solution in a liquid-to-solid ratio $(0.8: 1)$ by mechanically stirring for $4 \mathrm{~min}$. In the next step, the micro-silica sand was added to the geopolymer mixture and the mixture was stirred for an additional $2 \mathrm{~min}$. Finally, second silica sand was added to the mixture and the mixture was mixed for more $1 \mathrm{~min}$. The detail of geopolymer matrix mixture was shown in Table I.

TABLE I. MIXTURE OF GEOPOLYMER MORTAR MATRIX

\begin{tabular}{cccc}
\hline \multicolumn{4}{c}{ Mix ratio (by wt.\%) } \\
\hline Metakaolin & Activator & $\begin{array}{l}\text { Sand (grain size of } \\
0-0.065 \mathrm{~mm})\end{array}$ & $\begin{array}{l}\text { Sand (grain size of } \\
0.6-1.25 \mathrm{~mm} \text { ) }\end{array}$ \\
\hline 1 & 0.8 & 0.15 & 1.85 \\
\hline
\end{tabular}

The mechanical properties of the plain geopolymer matrix were obtained by the compressive, three-point bending, and splitting tensile tests. The three-point bending tests were conducted on $40 \times 40 \times 160 \mathrm{~mm}^{3}$ pris $\mathrm{m}$ specimens with test span $100 \mathrm{~mm}$, and then the compressive strengths were measured on the far edge of both residual pieces obtained from the flexural test. The splitting tensile tests were conducted on cylinder specimens with the diameter of $45 \mathrm{~mm}$ and length of $90 \mathrm{~mm}$. A total of 15 specimens for each test were prepared and tested at the age of 1,14 , and 28 days.

\section{B. Textile Reinforcements}

Six different types of textile (carbon mesh and basalt mesh) were used as a reinforcement, applied variants were shown in Fig. 1. The three different types of basalt mesh and carbon mesh corresponding to mesh sizes of $16 \times 12 \mathrm{~mm}, 25 \times 25 \mathrm{~mm}$, and $37 \times 37 \mathrm{~mm}$ were used in this study. The yarns in both directions of basalt textiles were composed of 2400 individual filaments and density of $2.75 \mathrm{~g} / \mathrm{cm}^{3}$. The carbon meshes with open size $16 \times 12 \mathrm{~mm}$ were made up of 48000 individual fila ments for the yarns in the longitudinal direction and 12000 individual filaments for yarns in the transverse direction, while the other two types of carbon mesh were made up of 48000 individual filaments for yarns in both directions, and density of $1.8 \mathrm{~g} / \mathrm{cm}^{3}$. The yarns of textiles were arranged in two orthogonal directions $\left(0^{\circ} / 90^{\circ}\right)$ to form textile and they were coated with styrene-butadiene binder.

\section{Manufacturing of Geopolymer Composite Plates}

In order to evaluate the four-point bending strength for geopolymer composite plates with embedded meshes (basalt and carbon meshes), specimens with a rectangular form with the dimensions of $360 \times 180 \times 20 \mathrm{~mm}^{3}$ (length, wide, thic kness) were prepared. The two layers of the same type of textiles were fixed in mold with the desired position, which mean that the cover mortar layer of thic kness $5 \mathrm{~mm}$ was applied to the bottom and top surface of the mold and between them the rest of mortar layer of thickness $10 \mathrm{~mm}$ was placed. The fresh prepared mortar matrix was poured into molds, vibrated for 1 min on the vibration table to remove air voids and covered with a thin plastic film to prevent the evaporation of water.
The total number of samples tested was 21 including nonreinforced reference samples (see Fig. 2). The samples prepared for test had a maturation period of 28 days.

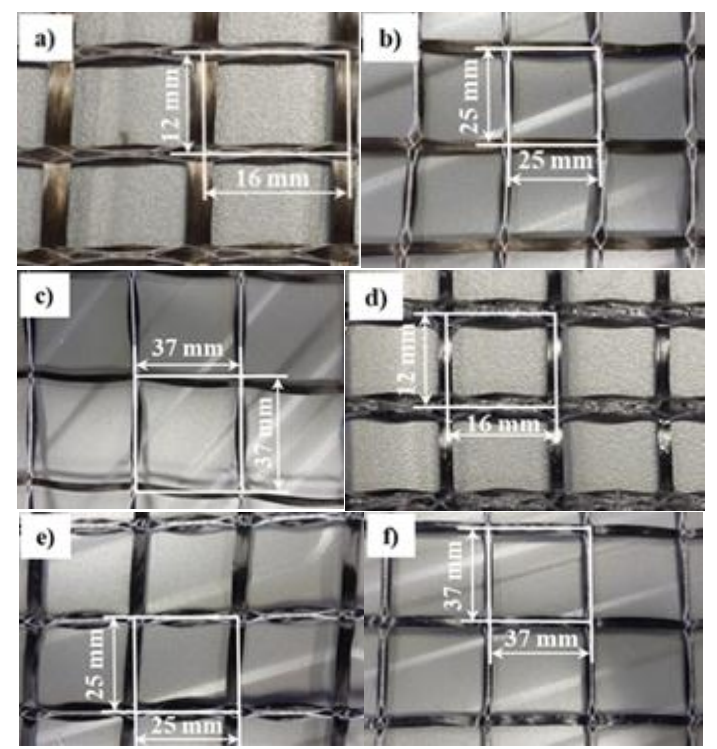

Fig. 1. The different types of reinforcement used: (a) Basalt mesh with aperture size of $16 \times 12 \mathrm{~mm}$; (b) Basalt mesh with aperture size of $25 \times 25$ $\mathrm{mm}$; (c) Basalt mesh with aperture size of $37 \times 37 \mathrm{~mm}$; (d) Carbon mesh of aperture size of $16 \times 12 \mathrm{~mm}$; (e) Carbon mesh of apert ure size of $25 \times 25 \mathrm{~mm}$; (f) Carbon mesh of aperture size of $37 \times 37 \mathrm{~mm}$

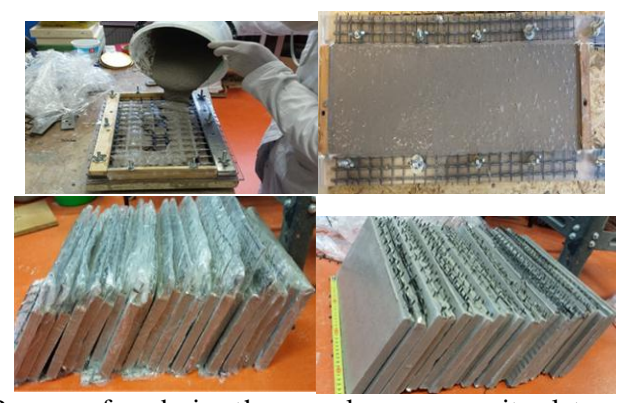

Fig. 2. Process of producing the geopolymer composite plates reinforced with textiles for four-points bending test.

A four-point bending test with constant bending moment zone was used to determine the bending strength of the panels. The illustration of the sample attachment and its fixation on the instrument was shown in Fig. 3. Three samples from each of the examined mesh types and mesh size were tested. For the safety reasons during the test, each sample was packaged with a foil (see Fig. 3). The calculation of the measured data and the evaluation of the test results were made using the following equation (3).

$$
\sigma \frac{F l}{b h^{2}}[\mathrm{MPa}]
$$

where $\sigma$ is the flexural strength in $\mathrm{MPa} ; \mathrm{F}$ is load at a given point on the load deflection curve in $\mathrm{N}$; $\mathrm{b}$ is the width of the tested sample in $\mathrm{mm}$; $\mathrm{h}$ is the thickness of tested sample in $\mathrm{mm}$; 1 is the support span in $\mathrm{mm}$.

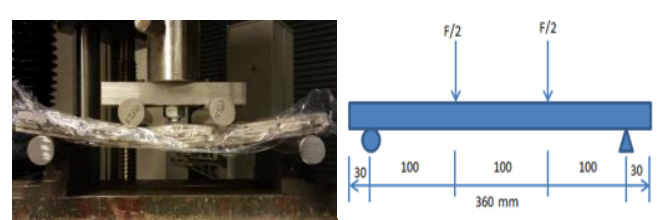

Fig. 3. Flexural strength test of geopolymer panels 


\section{RESUlTS AND DISCUSSION}

\section{A. The Mechanical Properties of Geopolymer Matrix}

Table 2 shows the mechanical properties of geopolymer mortar matrix at a time period of 1,14 and 28 days. It can be seen that the geopolymer mortar matrix cured at the room temperature reaches relatively high mechanical strengths at the age of 1 day after casting and its strength value gradually increases with increasing the curing age. After 28 days, the geopolymer mortar matrix has the compressive strength of 60.23 $\mathrm{MPa}$, the flexural strength of $11.08 \mathrm{MPa}$, and the splitting tensile strength of $4.8 \mathrm{MPa}$.

T ABLE II. RESULTS OF THE MECHANICAL PROPERTIES OF

\begin{tabular}{llll}
\multicolumn{4}{c}{ GEOPOLYMER MATRIX } \\
\hline Type & 1 day & 14 days & 28 days \\
\hline $\begin{array}{l}\text { Flexural strength } \\
{[\mathrm{MPa}]}\end{array}$ & $4.41 \pm 0.38$ & $8.9 \pm .63$ & $11.08 \pm 0.48$ \\
$\begin{array}{l}\text { Compressive } \\
\text { strength [MPa] }\end{array}$ & $27.66 \pm 1.01$ & $40.67 \pm 3.78$ & $60.23 \pm 3.79$ \\
$\begin{array}{l}\text { Splitting tensile } \\
\text { strength }[\mathrm{MPa}]\end{array}$ & $1.82 \pm 0.33$ & $4.27 \pm 0.52$ & $4.8 \pm 0.25$ \\
\hline
\end{tabular}

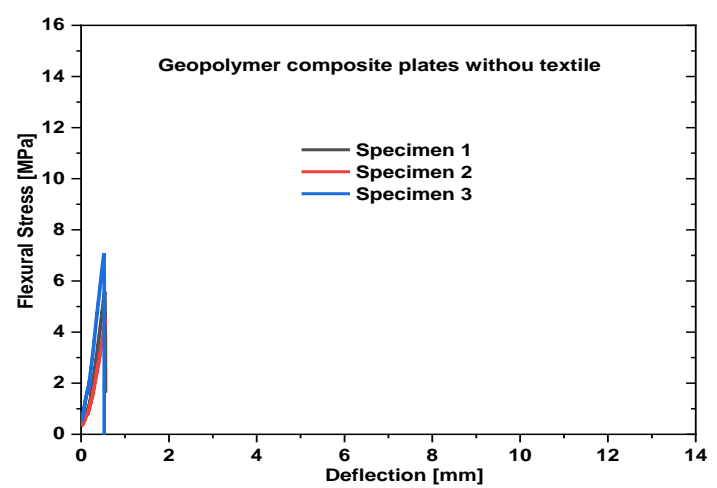

Fig. 4. Flexural stress and mid-span deflection curves of geopolymer plates without textiles.

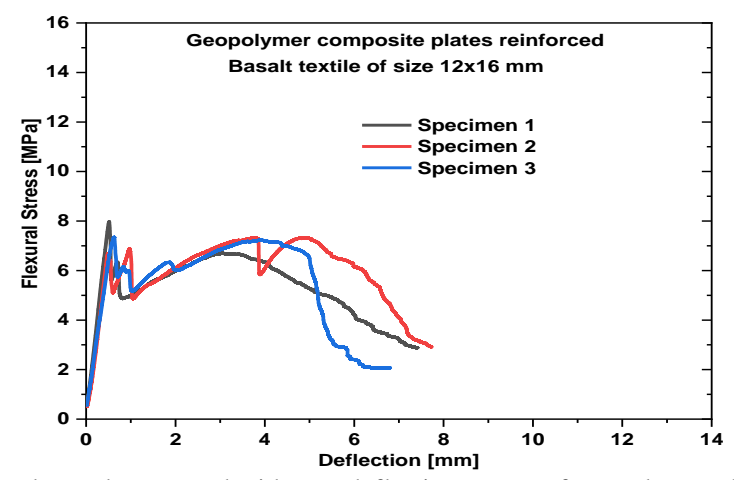

Fig. 5. Flexural stress and mid-span deflection curves of geopolymer plates reinforced basalt meshes of open size $12 \times 16 \mathrm{~mm}$.

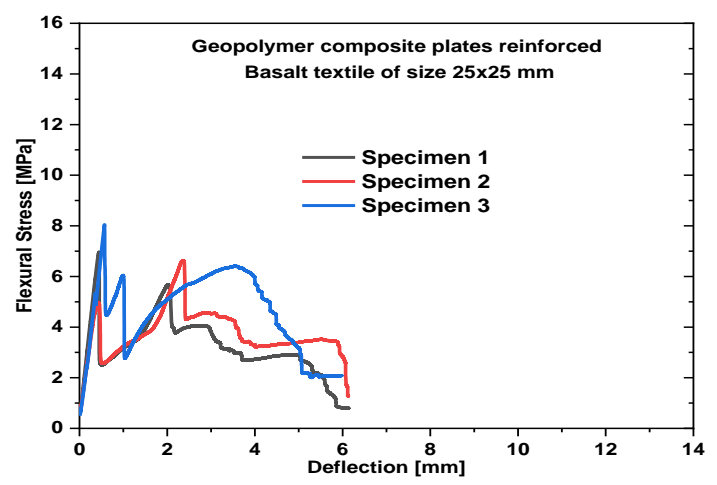

Fig. 6. Flexural stress and mid-span deflection curves of geopolymer plates reinforced basalt meshes of open size $25 \times 25 \mathrm{~mm}$.

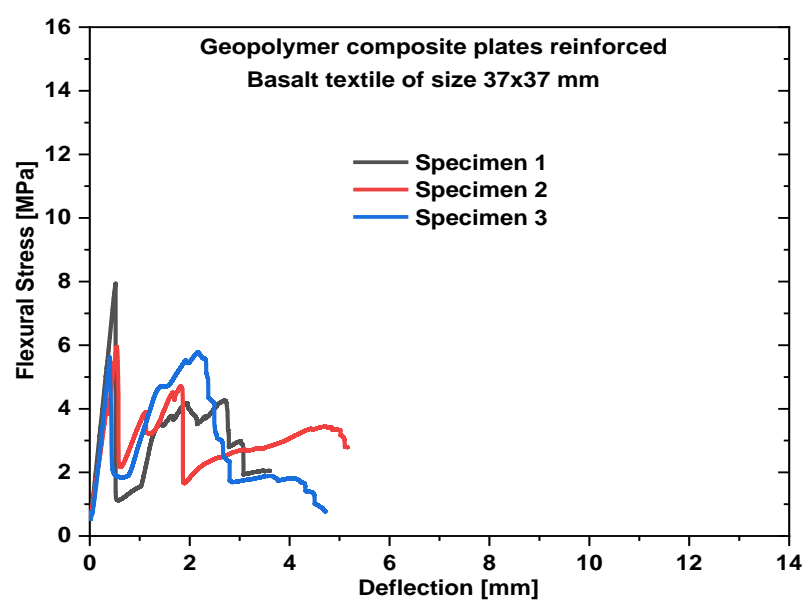

Fig. 7. Flexural stress and mid-span deflection curves of geopolymer plates reinforced basalt meshes of open size $37 \times 37 \mathrm{~mm}$.

\section{B. Flexural Behavior of Textiles Reinforced Geopolymer Composite Specimens}

An illustration of the course of four-point flexu ral tests of geopolymer composite panels has shown in the Fig. $4-10$. Fig. 4 shows the flexural stress-deflection curves of geopolymer panels without the meshes. The result shows a linear increase in measured values until the first crack is formed, followed by a sharp degradation of the samples. This result is due to the fact that geopolymer material without added fiber reinforcement is very brittle. The obtained average ultimate bending strength of this specimen is 5.78 MPa (see Fig. 11).

In Fig. 5, 6 and 7 shows the flexural stress-deflection curves of geopolymer composite panels with basalt meshes of aperture size $16 \times 12 \mathrm{~mm}$ (Fig. 5), of aperture size $25 \times 25$ mm (Fig. 6), and of aperture size $37 \times 37 \mathrm{~mm}$ (Fig. 7). Basalt textile reinforced geopolymer composites show a similar course in the flexural stress-deflection curve. It can be seen that the effect of two-layer basalt meshes reinforced in geopolymer mortar on the flexural strength of composite panels is not significant. After the first cracking, which is attributed to degradation of geopolymer matrix, therefore, its flexural strength decreases suddenly. Then, the flexural strength increases again with increasing in deflection. This behavior can be attributed to the basalt textiles. However, instead of forming multiple cracks in the conventional way of the composites of TRC, the first crack continues developing widen with increasing in deflection, then followed by breaking out of the yarns of the basalt textiles (see Fig. 15). This behavior can be explained by fact that the use of two layers of basalt textile performs insufficient distribution of the yarns in given thickness of geopolymer plate specimens. From Fig. 11 shows that the use of the basalt mesh with an aperture size $12 \times 16,25 \times 25$, and $37 \times 37$ reinforced geopolymer composite specimens has an ultimate flexural strength of $7.31 \mathrm{MPa}, 6.59 \mathrm{MPa}$, and $6.48 \mathrm{MPa}$, respectively.

Fig. 8, 9 and 10 shows the flexural stress-deflection behavior of geopoly mer composite panels with carbon mesh of aperture size $16 \times 12 \mathrm{~mm}$ (Fig. 8), of aperture size $25 \times 25$ mm (Fig. 9), and of aperture size $37 \times 37 \mathrm{~mm}$ (Fig. 10). In contrast to basalt textile reinforced geopolymer specimens, carbon textile reinforced composite specimens shows the 
similar fle xu ral stress-deflection behavior in the conventional way of the composites of TRC. The conventional behavior of TRC concrete is conducted in three stages. The first stage represents the linear uncracked state where the cementitious matrix takes the load. Then, as the load increases, the stress transfers from the cementitious matrix to the textile, which is represented by the multi-cracking process of the matrix. At the point or stage where the first crack takes the place is called the transition point. Then, the specimens continue to undergo a multi-cracking process, in which all of the stresses are transferred from matrix to textile. At this stage, the textile is only carrying until it fails by rupturing or by slipping [13]. In Fig. 8-10 it can be seen that the fle xural stress-deflection curves greatly depend on the type of mesh size of the reinforcing carbon textile. The specimens with a textile of smaller mesh size have higher flexural strength than those with textile of bigger mesh size, due to more distribution of the yarns in the same thickness size of composite specimens. Furthermore, at the multicracking-formation state, the stiffness of composite thin plates with carbon te xtile of $12 \times 16$ $\mathrm{mm}$ aperture size is stronger and that can be seen on the crack-widening state in Fig. 8, 9, 10, and 15. From the results obtained, it is apparent that the use of a carbon mesh with an aperture size of $16 \times 12 \mathrm{~mm}$ increases ultimate bending strength by $673.65 \%$; a carbon mesh with an aperture size 25 $\times 25 \mathrm{~mm}$ increases ultimate bending strength by $258.23 \%$ and a carbon mesh with an aperture size $3 \times 37 \mathrm{~mm}$ increases ultimate bending strength by $205.37 \%$ compared to nonreinforced reference specimens. However, mid-span deflection capacity at the average peak load of the specimens with three different mesh sizes is similar $10.34 \mathrm{~mm}, 10.25$ $\mathrm{mm}$ and $10.10 \mathrm{~mm}$, respectively (see Fig. 12 and 13).

The reinforcement efficiency of specimens can be evaluated by a factor indicating the ratio of the ultimate flexural strength of reinforced composite to the flexural strength of nonreinforced reference composite. The results obtained are shown in Fig. 14. As can be seen from data, the reinforcement efficiency depends on both types of textile and aperture size of textile. The excellent performance in the reinforcement efficiency obtained belongs to composite specimens with carbon mesh of aperture size $12 \times 16 \mathrm{~mm}$.

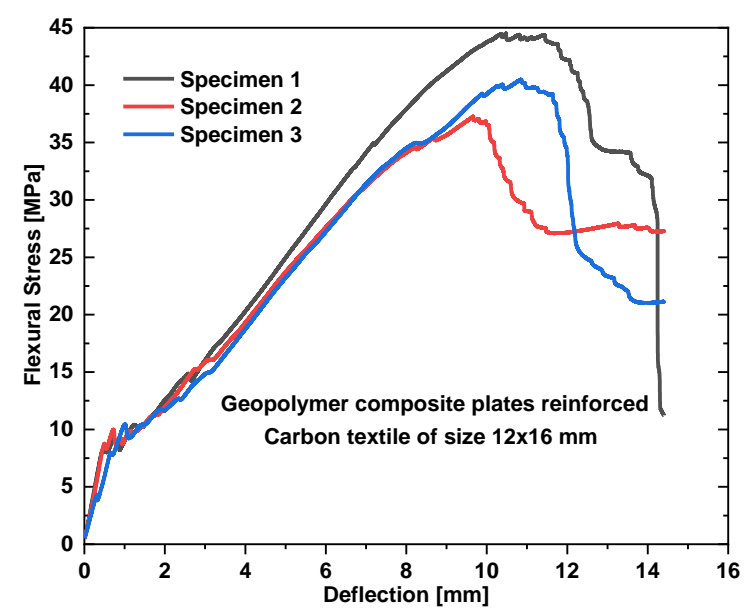

Fig. 8. Flexural stress and mid-span deflection curves of geopolymer plates reinforced carbon meshes of open size $12 \times 16 \mathrm{~mm}$.

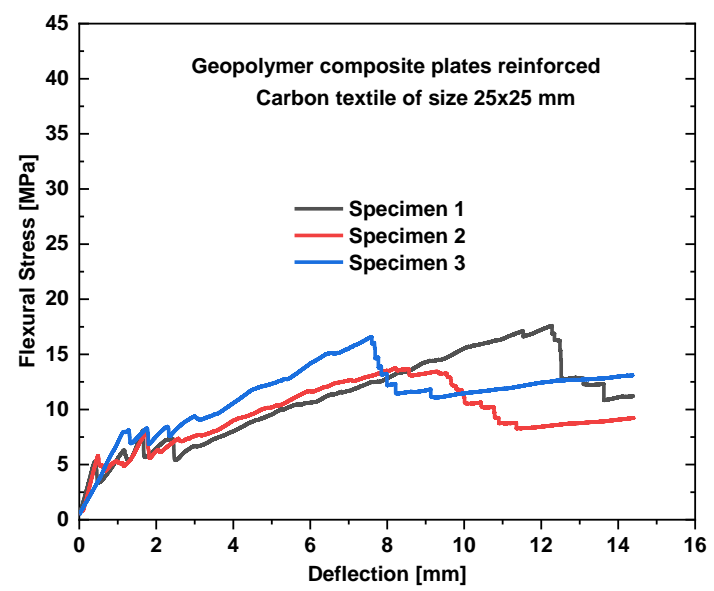

Fig. 9. Flexural stress and mid-span deflection curves of geopolymer plates reinforced carbon meshes of open size $25 \times 25 \mathrm{~mm}$.

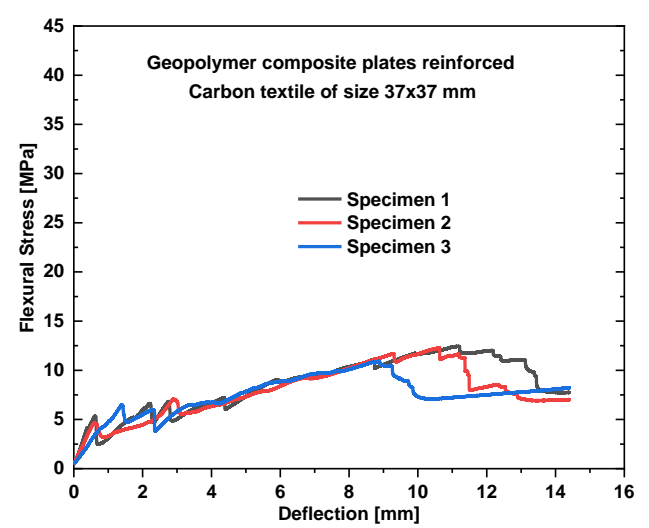

Fig. 10. Flexural stress and mid-span deflection curves of geopolymer plates reinforced carbon meshes of size $37 \times 37 \mathrm{~mm}$.

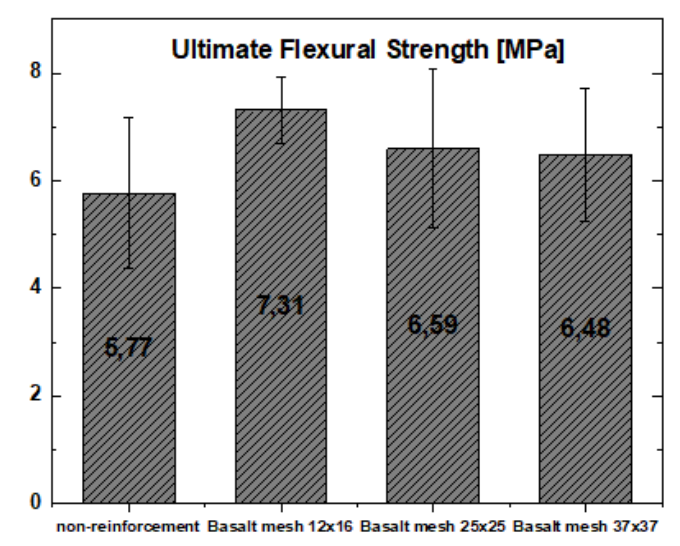

Fig. 11. Summary of four-point flexural strength of unreinforced specimens and basalt textiles reinforced composite specimens.

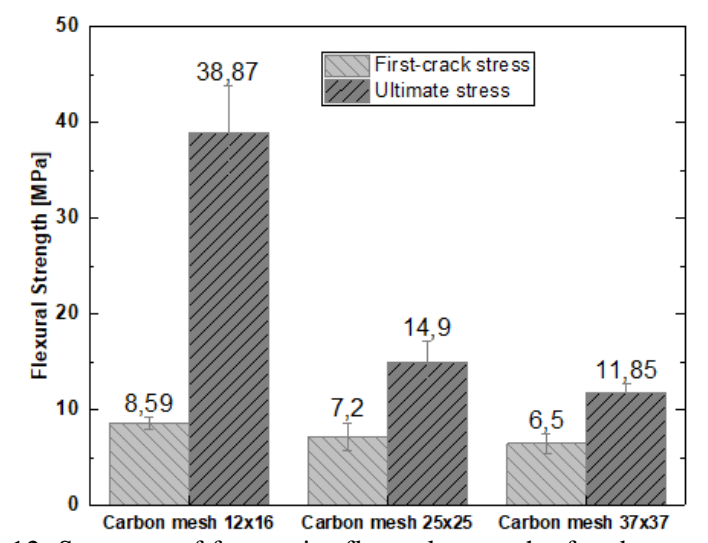

Fig. 12. Summary of four-point flexural strength of carbon textiles reinforced composite specimens. 


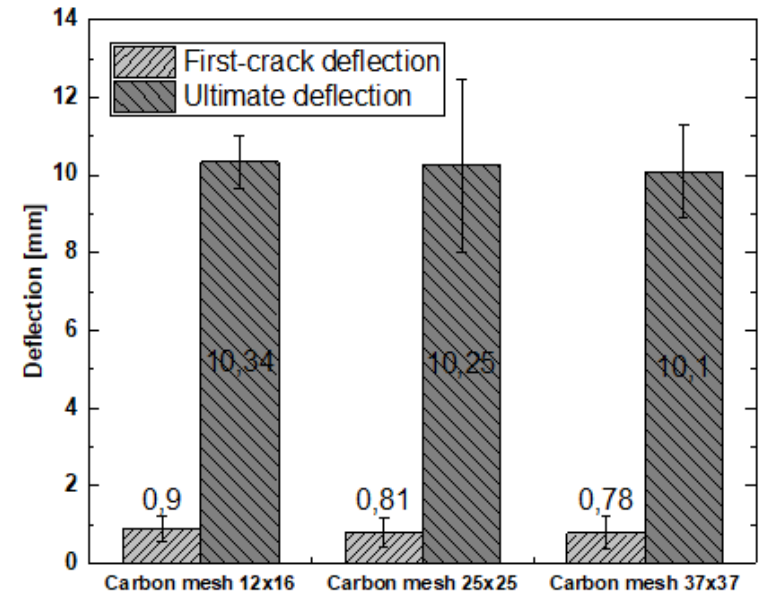

Fig. 13. Summary of deflection of carbon textiles reinforced composite specimens

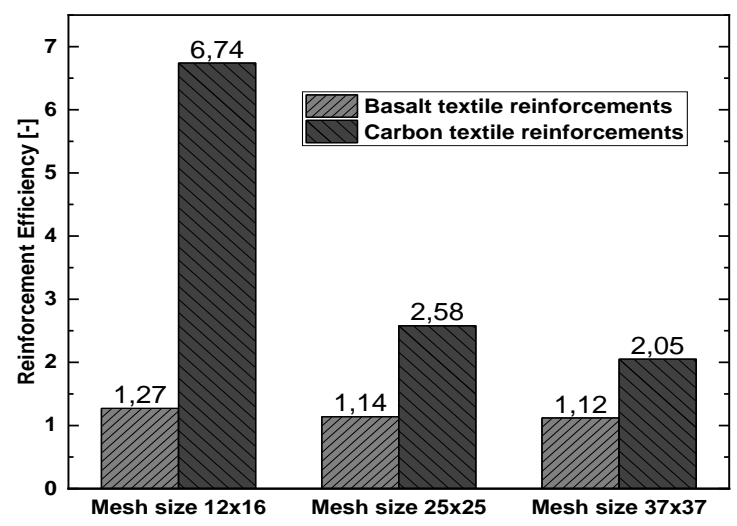

Fig. 14. The reinforcement efficiency of composite specimens.
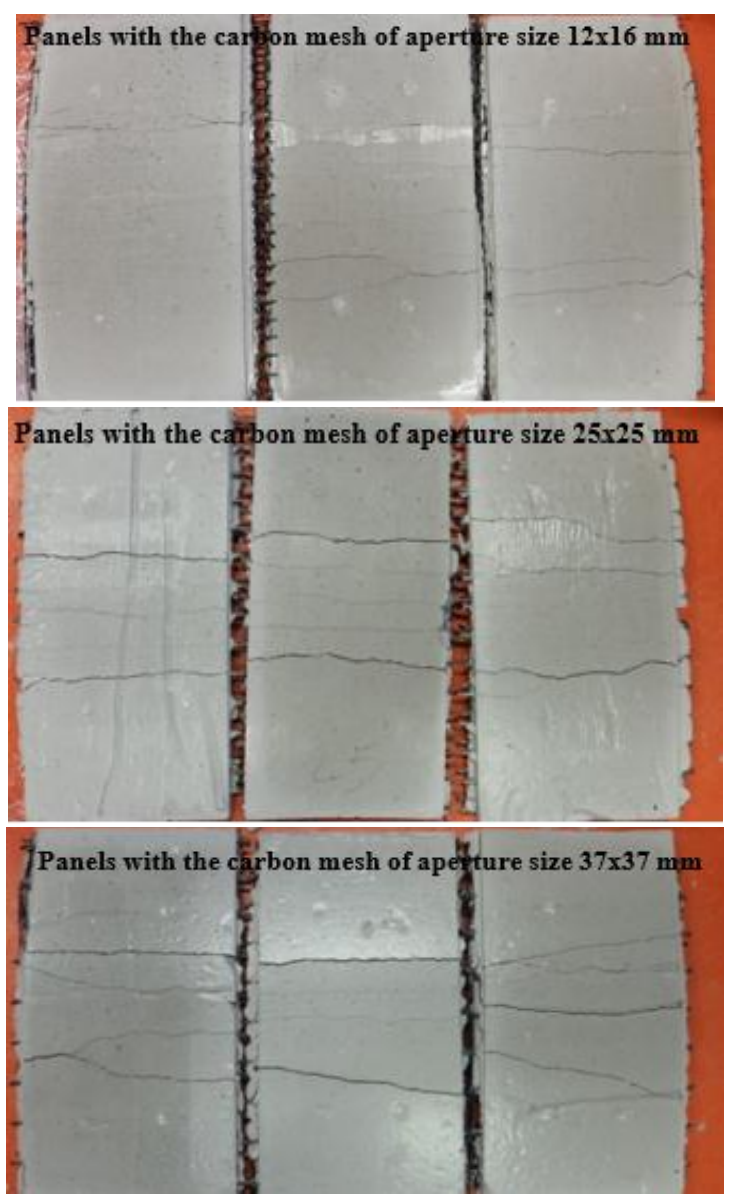

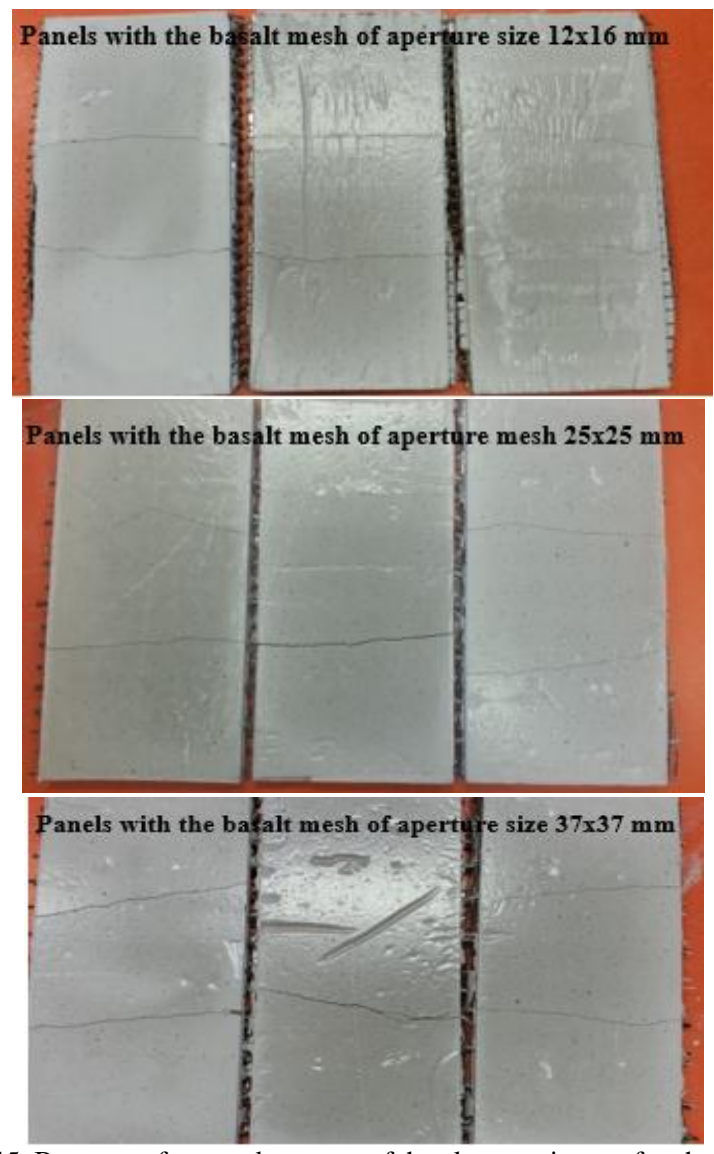

Fig. 15. Bott om surface crack patterns of the plate specimens after the end of testing.

\section{CONCLUSION}

In this research, the flexural strengthening of geopolymer composite thin plates reinforced with the different types of textile is represented. The paper focused on an experimental investigation of the effect of applying the two layers of basalt and carbon textiles obtained the different aperture sizes on the four-point flexu ral strength. From the results obtained, it can be concluded that:

Basalt meshes including the different three types of aperture size have no significant impact on the flexural strength of composite specimens as compared to control specimen without reinforcement. It can be explained that the use of two layers basalt textile reinforced in geopolymer matrix makes insufficient distribution of the yarns in the given thickness of composite specimens.

Carbon meshes have a significant impact on both the flexu ral strength and deflection of composite specimens. The composite specimens with smaller mesh size have stronger flexural strength than those with bigger mesh size. This is mainly due to more contribution of the yarns in the given same thickness of the specimens.

\section{ACKNOWLEDGMENT}

The results of the project "Application of geopolymer composites as fire, AGK", registration number VI20172019055, are obtained through the financial support of the Ministry of the interior in the program "The Safety Research of the Czech Republic" 2015-2020 (BV III/1-VS). 


\section{REFERENCES}

[1] V. Mechtcherine, "Novel cement-based composites for the strengthening and repair of concrete structures," Constr. Build. Mater. vol. 41, pp. 365-373, 2013.

[2] N. W. Portal, M. Flansbjer, K. Zandi, L. Wlasak, and K. Malaga, "Bending behaviour of novel Textile Reinforced Concrete-foamed concrete (TRC-FC) sandwich elements," Compos. Struct, vol. 177, pp. 104-118, 2017.

[3] V. Dey, G. Zani, M. Colombo, M. D. Prisco, and B. Mobasher, "Flexural impact response of textile-reinforced aerated concrete sandwich panels," Mater. Des., vol. 86, pp. 187-197,2015.

[4] I. G. Colombo, M. Colombo, and M. D. Prisco, "Bending behaviour of Textile Reinforced Concrete sandwich beams," Constr. Build. Mater. vol. 95, pp. 675-685, 2015.

[5] Y. H. M. Amran, R. S. M. Rashid, F. Hejazi, N. A. Safiee, and A. A. A. Ali, "Response of precast foamed concrete sandwich panels to flexural loading," J. Build. Eng., vol. 7, pp. 143-158, 2016.

[6] H. N. Atahan, B. Y. Pekmezci, and Y.T uncel, "Behavior of PVA fiber reinforced cementitious composites under static and impact flexural effects," J. Mater. Civ. Eng., no. October, p. 120922005613009, 2012.

[7] D. A. S. Rambo, F. D. A. Silva, R. D. T. Filho, and O. D. Fonseca M. Gomes, "Effect of elevated temperat ures on the mechanical behavior of basalt textile reinforced refractory concrete," Mater. Des., vol. 65 , pp. 24-33,2015.

[8] A. C. Constâncio Trindade, H. A. Alcamand, P. H. R. Borges, and F. D. A. Silva, "Influence of elevated temperatures on the mechanical behavior of jute-textile-reinforced geopolymers," J. Ceram. Sci. Technol., vol. 8, no. 3, pp. 389-398, 2017.

[9] D. L. Y. Kong, J. G. Sanjayan, and K. Sagoe-Crentsil, "Comparative performance of geopolymers made with metakaolin and fly ash after exposure to elevat ed temperatures," Cem. Concr. Res., vol. 37, no. 12, pp. 1583-1589, 2007.

[10] D. L. Y. Kong and J. G. Sanjayan, "Effect of elevated temperat ures on geopolymer paste, mort ar and concrete," Cem. Concr. Res., vol.40, no. 2, pp. 334-339, 2010.
[11] J. Davidovits, “Geopolymers: Ceramic-like inorganic polymers," J. Ceram. Sci. Technol., vol. 8, no. 3, pp. 335-350, 2017.

[12] P. J. Davidovits, "Properties of geopolymer cements," First Int. Conf. Alkaline Cem. Concr., pp. 131-149, 1994.

[13] A. Jabr, A. El-Ragaby, andF. Ghrib, "Effect of the fibertype and axial stiffness of FRCM on the flexural strengthening of RC beams," Fibers, vol. 5, no. 1, p. 2, 2017.

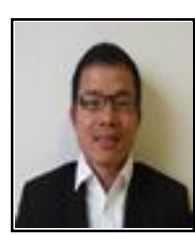

Hiep Le Chi was born in 1987. He has graduated with a bachelor's and master's degree in material engineering from the Technical University of Liberec, Czech Republic (2012 and 2015 respectively). He is currently pursing the $\mathrm{PhD}$ on the same department, Technical University of Liberec, Czech Republic. His field is mainly focused on the textiles reinforced in geopolymer composite. He is currently one of the members in the research team about two projects (application of geopolymer composites as fire barrier, AGK and geopolymer composites for improvement of the fire protection of population)

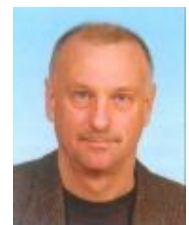

Petr Louda earned his master's degree from Technical University of Liberec, Czech Republic in 1984, and PhD title from University of West Bohemia in Plzen, Czech Republic in 1993; getting a full professor from Technical University of Liberec, Czech Republic 2005.

$\mathrm{He}$ is a current a head of Material Department of Mechanical Faculty, Technical University of Liberec. He has worked in many projects in the area of material engineering. He is the a head of research group in four projects (application of geopolymer composites as fire barier, AGK; geopolymer composites for improvement of the fire protection of population; dynamic multi-axis electro-hydraulic recovery units; development of a building insulation system from waste materials). 